\title{
A clinical view of analytical goals in clinical biochemistry
}

\author{
ANNE E. BARRETT, S. J. CAMERON, C. G. FRASER, L. A. PENBERTHY, AND \\ KAREN L. SHAND
}

From the Department of Clinical Biochemistry, Flinders Medical Centre, Bedford Park, South Australia 5042

SUMMARY The analytical goals inferred desirable by a group of clinicians for the imprecisions of a wide range of analytes have been studied by survey. The goals required have not in general become more stringent in the past decade and are not as demanding as those promulgated by laboratory professionals. Clinical biochemistry laboratories can now attain analytical imprecisions which satisfy the general demands of clinicians except for analyses of calcium and of low levels of glucose. The lack of published data on analytical goals does not allow wide comparison of criteria for performance standards with the results of this study.

One of the major philosophical problems in clinical biochemistry is the assessment of acceptable standards of analytical performance that must be achieved by routine service laboratories for optimal patient care at least expense. It has been stated that there is no one single set of analytical goals that can be promulgated which satisfies each and every individual clinical situation (International Federation of Clinical Chemistry, 1977); different analytical standards may be required, for example, for use in diagnosis, assessment of prognosis, screening, evaluation of therapy, and clinical emergencies. However, analytical performance goals have been proposed, including those based upon the reference range of particular analytes (Tonks, 1963), on the intra-individual variation of body fluid constituents (Cotlove et al., 1970; College of American Pathologists, 1976), on the state of the analytical art as evidenced from interlaboratory quality control schemes and proficiency surveys (Vanko, 1971; Duncan and Geary, 1973; Cresswell, 1975; Gilbert, 1975; Kurtz et al., .1977; Ross and Fraser, 1977), and on the results of surveys of clinical opinion (Barnett, 1968; Campbell and Owen, 1969).

No single criterion has proved totally satisfactory, and each of the above approaches has disadvantages. Reference ranges generated by individual laboratories are dependent on the analytical performance achieved; analytical goals for analytes such as drugs and for analytes at pathological levels cannot

Received for publication 6 March 1979 be obtained from assessment of normal biological individual variation; the state of the art merely reflects current standards achieved and not desirable performance; and the view of the clincian may in part reflect past experience with individual laboratories of rather different standards of performance.

In the present study, clinical opinion as to desirable analytical goals was surveyed for a far more extensive range of analytes than in previous similar studies. This study was carried out as a necessary prerequisite to studies concerning assessment of the rationale for requests of laboratory tests, the clinical actions taken as a result of test results, and the monitoring of clinician test request patterns. This study is thus a baseline assessment of current clinical opinion for use in concurrent and future research. The survey was also carried out in order to assess whether the clinical view had changed over the past decade, since the surveys of Barnett (1968) and Campbell and Owen (1969), to parallel the improvement in laboratory performance evidenced by inter-laboratory surveys. In addition, it was deemed of much interest to compare current clinical opinion with the recent consensus view on current analytical goals promulgated by an expert group (College of American Pathologists, 1976).

\section{Methods}

Medical staff of the Flinders Medical Centre, a general community and university teaching hospital, were all sent a questionnaire. The Flinders Medical 893 
Centre was selected as an ideal individual hospital for this study because all staff were appointed immediately before, or after, the commissioning of the Centre in 1976. Clinical staff had therefore been exposed previously to a wide variety of experiences with many laboratories of differing standards. In addition, the Department of Clinical Biochemistry had published and widely promulgated the actual analytical imprecisions found in the laboratories of the Centre.

The questionnaire listed the results of 25 laboratory tests. For all but two tests, cholesterol and triglyceride, two levels of analyte corresponding to the 'medically significant decision levels' of Barnett (1968) were nominated. The clinicians were asked to circle the one of five numerical results given that was considered to be a significant change in two consecutive results found in samples taken from a single untreated patient. The five results given were approximately one to five times the current laboratory standard deviation (SD) from the first result quoted (Table 1).

Table 1 Representative section of survey

\begin{tabular}{lllllll}
\hline Analyte & $\begin{array}{l}\text { Table I } \\
\text { 1st result }\end{array}$ & \multicolumn{4}{l}{$\begin{array}{l}\text { Table 2 } \\
\text { 2nd result } \\
\text { Circle significant change }\end{array}$} \\
\hline Sodium & 130 & 129 & 128 & 127 & 126 & 125 \\
Sodium & 145 & 146 & 147 & 148 & 149 & 150 \\
\hline
\end{tabular}

As a significant analytical difference in two consecutive laboratory results is, at $\mathrm{P}=0.95$, equivalent to 2.8 analytical SD (Whitby et al., 1975), the mode of the clinician survey responses was divided by $2 \cdot 8$ to infer the analytical SD desirable. The mode was chosen as this is the most frequent response elicited.

\section{Results}

A response of 62 replies from 150 questionnaires was received; this represented a $41.3 \%$ response. Of the 62 replies, 34, 7, 6, 6, and 9 were from clinicians who nominated medicine, surgery, obstetrics, paediatrics, and other specialties as their respective fields of interest or their present assignment. A statistical analysis of the responses on the basis of medical staff grade was not attempted as the numbers were considered inadequate.

No statistically significant differences between the goals desired by different groups of clinicians were found, and therefore all clinicians surveyed were treated as a single group.

The analytical performance desired by all clinicians with the level of analyte surveyed are shown in
Table 2 . The analytical goals detailed by clinicians in the studies of Barnett (1968) and Campbell and Owen (1969), and the goals promulgated by the College of American Pathologists (1976), are tabled for comparison as coefficients of variation (CV).

\section{Conclusions}

The poor response to this survey $(41.3 \%)$ may indicate that the majority of clinicians do not appreciate the importance of having knowledge of the analytical imprecisions of the methods that are used to generate results used in routine clinical practice. It may be that there is, as is often suspected, a severe communication barrier between laboratory and clinical staffs. These mainly semantic difficulties may be a major reason why certain preconceived ideas held by clinicians, which are evident in the results obtained by this survey, have not previously been corrected.

Although the analytical goals elicited from clinician survey data by Barnett (1968) and Campbell and Owen (1969) do have certain significant differences, for the few tests for which previous data are available it is evident that the clinical view of analytical goals desirable has not changed over the past decade, except for calcium, albumin, and glucose analyses for which a smaller imprecision is desired. This finding was unexpected as it was thought that most clinicians would be very aware of recent considerable technical advances, in large part occasioned by the wide use of mechanised analytical equipment.

For the analytes studied, except for creatine kinase, the imprecisions desired by clinicians are equal to or in general larger than the current analytical goals detailed by the College of American Pathologists (1976). This raises the very pertinent question whether clinical biochemists purchase and use expensive analytical equipment, test kits, and reagents, and use methods that give analytical results of a far higher standard than is truly necessary for routine clinical practice. We concur with the view that analytical goals should not be based only on the view of clinicians but emphasise that all goals are in large part subjective and should be subject to criticism, review, and experimental study in order to provide realistic goals for optimum patient care at least expense.

If the imprecisions tabled by Cresswell (1975), that is, those obtained by the least imprecise $10 \%$ of laboratories for each analyte in a large international quality control programme (the Wellcome Group Quality Control Programme) are considered to be a true reflection of the current state of the art, then the least imprecise laboratories can indeed satisfy 
Table 2 Analytical performance desired and comparison with published data

\begin{tabular}{|c|c|c|c|c|c|c|}
\hline \multirow[t]{2}{*}{ Analyte } & \multirow[t]{2}{*}{ Level surveyed } & \multicolumn{2}{|c|}{ Imprecision required-mode } & \multirow{2}{*}{$\begin{array}{l}\text { Barnett (1968) } \\
\text { CV }(\%)\end{array}$} & \multirow{2}{*}{$\begin{array}{l}\text { Campbell and } \\
\text { Owen }(1969) \\
\text { CV }(\%)\end{array}$} & \multirow{2}{*}{$\begin{array}{l}C A P(1976) \\
C V(\%)\end{array}$} \\
\hline & & $S D$ & $C V(\%)$ & & & \\
\hline Sodium & $130 \mathrm{mmol} / 1$ & $1 \cdot 8$ & $1 \cdot 4$ & $1 \cdot 5$ & \multirow{2}{*}{$0 \cdot 7$} & \multirow{2}{*}{$0 \cdot 4$} \\
\hline Sodium & $145 \mathrm{mmol} / 1$ & $1 \cdot 8$ & $1 \cdot 3$ & $1 \cdot 3$ & & \\
\hline Potassium & $3.0 \mathrm{mmol} / 1$ & $0 \cdot 11$ & $3 \cdot 7$ & $8 \cdot 3$ & \multirow{2}{*}{1.9} & \multirow{2}{*}{$2 \cdot 2$} \\
\hline Potassium & $5.0 \mathrm{mmol} / 1$ & $0 \cdot 11$ & $2 \cdot 2$ & $4 \cdot 2$ & & \\
\hline Chloride & $85 \mathrm{mmol} / 1$ & $1 \cdot 1$ & $1 \cdot 3$ & $2 \cdot 2$ & \multirow{2}{*}{-} & \multirow{3}{*}{$1 \cdot 1$} \\
\hline Chloride & $115 \mathrm{mmol} / 1$ & $1 \cdot 8$ & 1.6 & $1 \cdot 8$ & & \\
\hline $\mathrm{CO}_{2}$ & $20 \mathrm{mmol} / \mathrm{l}$ & 1.8 & $9 \cdot 0$ & $5 \cdot 0$ & \multirow{2}{*}{ - } & \\
\hline $\mathrm{CO}_{2}$ & $35 \mathrm{mmol} / 1$ & $1 \cdot 1$ & $3 \cdot 1$ & $3 \cdot 3$ & & 一 \\
\hline Urea & $3.0 \mathrm{mmol} / 1$ & 0.45 & $15 \cdot 0$ & \multirow[t]{2}{*}{$7 \cdot 4$} & \multirow{2}{*}{$3 \cdot 7$} & \multirow{2}{*}{$6 \cdot 2$} \\
\hline Urea & $9.0 \mathrm{mmol} / 1$ & 0.89 & 9.9 & & & \\
\hline $\begin{array}{l}\text { Creatinine } \\
\text { Creatinine }\end{array}$ & $\begin{array}{l}0.05 \mathrm{mmol} / 1 \\
0.13 \mathrm{mmol} / 1\end{array}$ & $\begin{array}{l}0.007 \\
0.020\end{array}$ & $\begin{array}{l}14 \cdot 0 \\
15.4\end{array}$ & \multirow[t]{2}{*}{ 一 } & \multirow[t]{2}{*}{$4 \cdot 0$} & \multirow[t]{2}{*}{$2 \cdot 2$} \\
\hline Calcium & $2 \cdot 10 \mathrm{mmol} / 1$ & 0.018 & 0.86 & & & \\
\hline Calcium & $2.60 \mathrm{mmol} / 1$ & 0.021 & $0 \cdot 81$ & $2 \cdot 3$ & $7 \cdot 7$ & 0.9 \\
\hline Phosphate & $0.50 \mathrm{mmol} / 1$ & 0.05 & $10 \cdot 0$ & $5 \cdot 6$ & - & $2 \cdot 9$ \\
\hline Phosphate & $1.25 \mathrm{mmol} / 1$ & 0.05 & $4 \cdot 0$ & & & \\
\hline Protein & $62 \mathrm{~g} / 1$ & $1 \cdot 8$ & $2 \cdot 9$ & $4 \cdot 3$ & $2 \cdot 2$ & $1 \cdot 5$ \\
\hline Protein & $85 \mathrm{~g} / 1$ & 1.8 & $2 \cdot 1$ & & & \\
\hline Albumin & $30 \mathrm{~g} / 1$ & $1 \cdot 1$ & $3 \cdot 7$ & $7 \cdot 1$ & - & $1 \cdot 4$ \\
\hline Albumin & $52 \mathrm{~g} / 1$ & 1.8 & $3 \cdot 5$ & & & \\
\hline Bilirubin & $20 \mu \mathrm{mol} / 1$ & $2 \cdot 1$ & $10 \cdot 5$ & 20.0 & $3 \cdot 3$ & - \\
\hline Bilirubin & $300 \mu \mathrm{mol} / 1$ & $17 \cdot 9$ & 6.0 & $7 \cdot 4$ & $2 \cdot 4$ & \\
\hline Alkaline phosphatase & $125 \mathrm{U} / 1$ & $5 \cdot 4$ & $4 \cdot 3$ & - & - & 1.8 \\
\hline Alkaline phosphatase & $250 \mathrm{U} / 1$ & 8.9 & $3 \cdot 6$ & - & - & 10 \\
\hline Alanine aminotransferase & $35 \mathrm{U} / 1$ & 3.6 & $10 \cdot 3$ & - & - & - \\
\hline Alanine aminotransferase & $70 \mathrm{U} / 1$ & 8.9 & $12 \cdot 7$ & - & - & - \\
\hline Glucose & $2.2 \mathrm{mmol} / \mathrm{l}$ & 0.07 & $3 \cdot 2$ & $10 \cdot 0$ & & \\
\hline Glucose & $6.6 \mathrm{mmol} / 1$ & $0 \cdot 18$ & $2 \cdot 7$ & $4 \cdot 2$ & $2 \cdot 3$ & $2 \cdot 2$ \\
\hline Amylase & $300 \mathrm{U} / 1$ & $17 \cdot 9$ & $6 \cdot 0$ & - & - & - \\
\hline Amylase & $900 \mathrm{U} / 1$ & $89 \cdot 3$ & $9 \cdot 9$ & - & 一 & 一 \\
\hline Urate & $0.12 \mathrm{mmol} / 1$ & 0.018 & $15 \cdot 0$ & $8 \cdot 3$ & $1 \cdot 7$ & $3 \cdot 7$ \\
\hline Urate & $0.58 \mathrm{mmol} / 1$ & 0.018 & $3 \cdot 1$ & $8 \cdot 3$ & 1.7 & $3 \cdot 1$ \\
\hline Creatine kinase & $140 \mathrm{U} / 1$ & $7 \cdot 1$ & $5 \cdot 1$ & - & - & $13 \cdot 0$ \\
\hline Creatine kinase & $220 \mathrm{U} / 1$ & 8.9 & $4 \cdot 1$ & - & - & \\
\hline Hydroxybutyrate & & & & & & \\
\hline dehydrogenase & $250 \mathrm{U} / 1$ & 8.9 & 3.6 & - & - & - \\
\hline Hydroxybutyrate & & & & & - & \\
\hline dehydrogenase & $500 \mathrm{U} / 1$ & $17 \cdot 9$ & $3 \cdot 6$ & & & \\
\hline pH & $7 \cdot 30$ & 0.011 & $2 \cdot 8$ & - & - & - \\
\hline pH & $7 \cdot 48$ & 0.007 & $1 \cdot 2$ & - & - & - \\
\hline $\mathrm{PCO}_{2}$ & $32 \mathrm{~mm} \mathrm{Hg}$ & $1 \cdot 4$ & $4 \cdot 4$ & - & - & - \\
\hline $\mathbf{P C O}_{2}$ & $48 \mathrm{~mm} \mathrm{Hg}$ & $2 \cdot 1$ & $4 \cdot 4$ & & & \\
\hline $\mathrm{Po}_{2}$ & $75 \mathrm{~mm} \mathrm{Hg}$ & 3.6 & $4 \cdot 8$ & - & - & - \\
\hline $\mathrm{PO}_{2}$ & $110 \mathrm{~mm} \mathrm{Hg}$ & 1.8 & 1.6 & & & \\
\hline Osmolality & $280 \mathrm{mmol} / \mathrm{kg}$ & 3.6 & $1 \cdot 3$ & - & - & - \\
\hline Osmolality & $300 \mathrm{mmol} / \mathrm{kg}$ & 3.6 & $1 \cdot 2$ & & - & - \\
\hline Thyroxine & $65 \mathrm{nmol} / 1$ & 3.6 & $5 \cdot 5$ & 一 & - & $3 \cdot 8$ \\
\hline Thyroxine & $145 \mathrm{nmol} / \mathrm{l}$ & $5 \cdot 4$ & $3 \cdot 7$ & $8 \cdot 0$ & 1.8 & $2 \cdot 4$ \\
\hline Cholesterol & $6.5 \mathrm{mmol} / 1$ & $0 \cdot 18$ & $2 \cdot 8$ & $\begin{array}{l}8.0 \\
-\end{array}$ & $\frac{1.8}{-}$ & $\begin{array}{r}2.4 \\
13.0\end{array}$ \\
\hline Triglyceride & $1.7 \mathrm{mmol} / 1$ & $0 \cdot 18$ & $10 \cdot 5$ & 一 & 一 & 13.0 \\
\hline
\end{tabular}

the desirable imprecision performance goals inferred by clinicians, except in the case of calcium and glucose at low levels, with present equipment and methods.

The imprecisions obtained for 14 analytes by laboratories participating in the 1975 Quality Assurance Service of the College of American Pathologists have been documented by Ross and Fraser (1977). This survey confirms the evidence obtained from the results of many inter-laboratory quality assurance schemes, that manual methods have larger imprecisions in general than mechanised methods. Manual techniques for determination of albumin, low levels of bilirubin, calcium, chloride, cholesterol, phosphate, and low levels of urate have imprecisions that are greater than the mode desired by clinicians, and mechanised techniques for determination of albumin, calcium, chloride, and cholesterol have greater imprecisions than the mode desired. It is therefore concluded that while the least imprecise biochemistry laboratories can satisfy clinical criteria with regard to imprecision, certain laboratories, notably those using manual techniques, have inadequate imprecision performance standards 
for a number of commonly requested analytes.

This survey has not sought justification for the analytical goals indirectly proposed by clinicians, and certain statements inferred are of interest and illustrate further topics for research in this abstruse area. Current clinical opinion is that plasma creatinine levels may be a better index of renal function than plasma urea levels, but the imprecision desired for plasma creatinine is larger than that desired for plasma urea. This may be because laboratories can indeed estimate plasma urea with less imprecision than plasma creatinine (see, for example, Ross and Fraser (1977)), and clinical opinion is very much influenced by actual present laboratory performance. Analogous reasoning may explain the small imprecision desired by clinicians for plasma sodium determination; laboratories can measure sodium levels with small imprecision but it could be argued that this excellent analytical performance is not really necessary in present clinical practice.

Analytical goals for many of the analytes studied in the present survey have not been detailed previously because such analytes as blood gases are not assessed in inter-laboratory quality assurance schemes and are not easily studied with regard to their biological variation. We recognise the deficiencies of clinician surveys but it is hoped that the results of this study will stimulate discussion and experimental work on desirable performance characteristics for a wide range of analytes.

All clinical staff of the Flinders Medical Centre who completed the survey paper are thanked for their assistance.

\section{References}

Barnett, R. N. (1968). Medical significance of laboratory results. American Journal of Clinical Pathology, 50, 671-676.
Campbell, D. G., and Owen, J. A. (1969).The physician's view of laboratory performance. Australian Annals of Medicine, 18, 4-6.

College of American Pathologists (1976). Goals in Clinical Chemistry: Proceedings of the 2nd Annual Aspen Conference, p. 4. Aspen, Colorado.

Cotlove, E., Harris, E. K., and Williams, G. Z. (1970). Biological and analytic components of variation in long-term studies of serum constituents in normal subjects. III. Physiological and medical implications. Clinical Chemistry, 16, 1028-1032.

Cresswell, M. A. (1975). How useful is the clinical chemistry laboratory? Lab-Lore, 6, 353-356.

Duncan, B. M., and Geary, T. D. (1973). A method for analysing results of medical laboratory proficiency surveys. Pathology, 5, 91-98.

Gilbert, R. K. (1975). Progress and analytic goals in clinical chemistry. American Journal of Clinical Pathology, 63, 960-973.

International Federation of Clinical Chemistry (1977). Provisional recommendation on quality control in clinical chemistry. Part 6. Quality requirements from the point of view of health care. Clinica Chimica Acta, 74, F1-F6.

Kurtz, S. R., Copeland, B. E., and Straumfjord, J. V., Jr. (1977). Guidelines for clinical chemistry quality control based on the long-term experience of sixty-one university and tertiary care referral hospitals. A reappraisal. American Journal of Clinical Pathology, 68 , 463-473.

Ross, J. W., and Fraser, M. D. (1977). Analytical clinical chemistry precision. State of the art for fourteen analytes. American Journal of Clinical Pathology, 68, $130-141$.

Tonks, D. B. (1963). A study of the accuracy and precision of clinical chemistry determinations in 170 Canadian laboratories. Clinical Chemistry, 9, 217-223.

Vanko, M. (1971). In Advances in Automated Analysis, Vol. 1, p. 159. Mediad, White Plains, N.Y.

Whitby, L. G., Percy-Robb, I. W., and Smith, A. F. (1975). Lecture Notes on Clinical Chemistry, p. 26. Blackwell, Oxford.

Requests for reprints to: Dr C. G. Fraser, Department of Clinical Biochemistry, Flinders Medical Centre, Bedford Park, South Australia 5042. 